\title{
Literacy and Informed Consent:
}

\section{A Case for Literacy Screening in Glaucoma Research}

\author{
Kelly W. Muir, MD and Paul P. Lee, MD, JD
}

The National Adult Literacy Survey of 1992 alerted educators and policymakers to a previously underrecognized problem: nearly one-fourth of the American adult population is functionally illiterate. ${ }^{1}$ More recently, the medical community has become aware of the prevalence of inadequate health literacy, or the inability to comprehend written material in a health care setting. In 1 study involving more than 2500 patients in 2 urban hospitals, $42 \%$ of subjects could not understand written instructions for taking medication on an empty stomach. ${ }^{2}$ Importantly, functional health literacy is lower in older age cohorts in the United States. ${ }^{3}$ In a sample of English-speaking adults aged 60 years and older, less than $20 \%$ demonstrated adequate health literacy skills. ${ }^{2}$ The age-related decline in health literacy skills persists even when cognitive function is taken into account. ${ }^{3}$ Although educational attainment and literacy are not interchangeable, the 2 concepts are closely related (average reading skills are generally 3-5 grade levels lower than the last year of school completed). The US Census Bureau data from 2007 reveal that $86 \%$ of Americans aged 18 to 74 years identify themselves as high school graduates compared with only $73 \%$ of Americans aged 75 years and older. ${ }^{4}$ Societal constraints on educational attainment may help explain this discrepancy. A child aged 14 years in 1936 in the middle of the Great Depression may not have had the opportunity to complete high school. That same child would have been aged 85 years in 2007.

Why is literacy of particular concern in the glaucoma population? Glaucoma is largely a disease of older adults. Of the estimated 2.2 million American adults with glaucoma, approximately $86 \%$ are aged 60 years or older. As the American population ages, the number of people with glaucoma is expected to grow steadily. The prevalence of glaucoma increases from 1.6 per 100 people in the population aged 60 to 64 years, to 7.7 per 100 people for those aged 80 years and older. ${ }^{5}$ Given the burden of poor literacy in the older American population, it is not surprising that in a sample of 200 people with glaucoma, $52 \%$ read at or below an eighth-grade level and $12 \%$ read at or below a third-grade level. ${ }^{6}$

Poor literacy influences patients' health and the health care system in many ways. Poor health literacy is associated with more frequent hospital admissions ${ }^{7}$ and is an independent predictor of increased mortality. ${ }^{8}$ It was recently reported that poor health literacy is associated with worse visual field outcomes in patients with glaucoma. ${ }^{9}$ The relationship between literacy and participation in clinical research is less well understood. Several studies have found that higher levels of educational attainment are associated with increased willingness to participate in clinical trials,,${ }^{10,11}$ while at least 1 study has found no association between education and research participation. ${ }^{12}$

Potential subjects with poor health literacy may be unfairly excluded from clinical research. Feelings of shame and a reluctance to disclose reading difficulties often accompany low

(C2009 American Medical Association. All rights reserved.

Correspondence: Dr Muir, Duke University Medical Center, Box 3802, Durham, NC 27710 (kelly.muir@duke.edu).

Financial Disclosure: None reported. 
literacy status, ${ }^{13}$ and less-literate people may decline to engage in research activities that might challenge or expose their literacy skills. Well-intentioned investigators may unknowingly facilitate this selection bias. Poor vision is a common exclusion criterion in clinical trials, but nonophthalmologic trials do not often require formal acuity testing. Lessliterate adults may claim poor vision as a coping strategy when presented with written material.

Less-literate subjects may be inappropriately excluded under new privacy regulations for study recruitment. With institutional review board (IRB) rules requiring patient notification and affirmative action for involvement in almost all studies, literacy can be a major obstacle to participation. If a patient at a third-grade reading level receives a letter written at an eighth-grade level informing him of the opportunity to participate in a clinical trial, it is reasonable to assume that he might not respond. Likewise, if the same person receives a letter written at the same level informing him of a population-based study in his area, for which assent is assumed unless he opts out, he may find himself participating in a study to which he might object, if well informed.

Although ideally informed consent is a process of sharing and discussing the risks and benefits of the research at hand, the culmination of the process is the signing of a written document by the research subject. Achieving appropriate readability and including all the required language in an informed consent document is a challenge not often won. In a 2003 survey of 114 US medical schools, the average readability score for the sample text provided by the schools' IRBs was 10.6 (10th- to 11 thgrade reading level). The readability required by the same IRBs for informed consent documents, however, ranged from fifth to 10th grade. Unfortunately, little has changed since 2003. For example, 1 IRB in our region requests that proposed informed consent documents be written at a sixth-grade level, but if one includes only the text required by the IRB, the readability score already exceeds the 14th-grade level.

Simplifying the language of informed consent documents, however, may not fully address the problems posed to clinical research by poor health literacy. When a sample of adults was given 2 different informed consent documents explaining a hypothetical cancer trial, 1 written at a seventh-grade and 1 at a 16th-grade level, most subjects preferred the simpler document, regardless of their level of literacy. However, the only factor that influenced the subjects' understanding of the hypothetical study was the subjects' own level of literacy. ${ }^{14}$

If a written document inadequately informs potential subjects of the necessary details of a research study, perhaps alternative approaches are indicated. Although potential research subjects preferred a videotaped explanation of the relevant information over a written document, ${ }^{15}$ a systematic review of various interventions aimed at improving comprehension in the informed consent process showed that multimedia technology did not surpass the success of one-on-one time with a knowledgeable educator. ${ }^{16}$

Ideally, the informed consent process for a potential subject in a glaucoma trial would begin with an assessment of competency, most conveniently via a computerized program, followed by an assessment of health literacy. Although no computerized assessments of health literacy are commercially available, one of the most widely used testing instruments, the Rapid Assessment of Adult Literacy in Medicine (REALM), takes only 2 to 3 minutes to administer. The REALM is a reading recognition test composed of 66 health-related words. The subjects read the words aloud and the interviewer scores the test based on which words are pronounced correctly. The REALM score can be used to stratify health literacy levels into third grade or below, fourth to sixth grade, seventh to eighth grade, and ninth grade and above. ${ }^{17}$ With this information, an informed consent document and accompanying 
explanatory DVD can be generated, targeted to the subject's literacy level. Informed consent discussion can be tailored to those with low literacy using teach-back (asking the learner to repeat to the teacher what he or she understands, in his or her own words) and pictures, for example, which have been shown to increase comprehension for lessliterate adults. ${ }^{18}$

Twenty years ago, only a handful of clinical trials in glaucoma care existed. Today, 133 glaucoma trials are listed as active at http://clinicaltrials.gov. More patients with glaucoma than ever will have the opportunity to participate in clinical trials, but the elderly segment of the population, which is most affected by glaucoma, is also the age group least likely to partake in clinical research. ${ }^{19}$ Others have suggested literacy screening for trial enrollment, ${ }^{20}$ but the practice has not been widely adopted. The field of glaucoma research has the opportunity to lead the way in incorporating literacy screening into the informed consent process. Although a testing instrument such as REALM may add 2 to 3 minutes to the process, the information gained can help guide the informed consent discussion and the written materials involved, potentially saving time, increasing the diversity of clinical trial participants, and, most importantly, improving participants' comprehension of the research.

\section{Acknowledgments}

Funding/Support: Dr Muir receives financial support from the National Institutes of Health in the form of an institutional training grant (5K12-EY-016333-05). The funding organization did not have a role in the design of the manuscript.

\section{REFERENCES}

1. Kirsch, I.; Jungeblut, A.; Jenkins, L.; Kolstad, A. Adult Literacy in America: A First Look at the Findings of the National Adult Literacy Survey. Washington, DC: National Center for Education Statistics, US Dept of Education; 1993.

2. Williams MV, Parker RM, Baker DW, et al. Inadequate functional health literacy among patients at two public hospitals. JAMA. 1995; 274(21):1677-1682. [PubMed: 7474271]

3. Baker DW, Gazmararian JA, Sudano J, Patterson M. The association between age and health literacy among elderly persons. J Gerontol B Psychol Sci Soc Sci. 2000; 55(6):S368-S374. [PubMed: 11078114]

4. [Accessed June 16, 2008] Educational Attainment of the Population 18 Years and Over, by Age, Sex, Race, and Hispanic Origin:2007. US Census Bureau. Educational Attainment in the United States. Current Population Survey, 2007 Annual, Social, and Economic Supplement. http:// www.census.gov/population/socdemo/education/cps2007/Table101.xls

5. Friedman DS, Wolfs RC, O’Colmain BJ, et al. Eye Diseases Prevalence Research Group. Prevalence of open-angle glaucoma among adults in the United States. Arch Ophthalmol. 2004; 122(4):532-538. [PubMed: 15078671]

6. Muir KW, Santiago-Turla C, Stinnett SS, et al. Health literacy and adherence to glaucoma therapy. Am J Ophthalmol. 2006; 142(2):223-226. [PubMed: 16876500]

7. Baker DW, Gazmararian JA, Williams MV, et al. Functional health literacy and the risk of hospital admission among Medicare managed care enrollees. Am J Public Health. 2002; 92(8):1278-1283. [PubMed: 12144984]

8. Baker DW, Wolf MS, Feinglass J, Thompson JA, Gazmararian JA, Huang J. Health literacy and mortality among elderly persons. Arch Intern Med. 2007; 167(14):1503-1509. [PubMed: 17646604]

9. Juzych MS, Randhawa S, Shukairy A, Kaushal P, Gupta A, Shalauta N. Functional health literacy in patients with glaucoma in urban settings. Arch Ophthalmol. 2008; 126(5):718-724. [PubMed: 18474786]

10. Grann VR, Jacobson JS, Troxel AB, et al. Barriers to minority participation in breast carcinoma prevention trials. Cancer. 2005; 104(2):374-379. [PubMed: 15937913] 
11. Van de Ven P, Mao L, Crawford J, et al. Willingness to participate in HIV vaccine trials among HIV-negative gay men in Sydney, Australia. Int J STD AIDS. 2005; 16(4):314-317. [PubMed: 15899086]

12. Corbie-Smith G, Viscoli CM, Kernan WN, Brass LM, Sarrel P, Horwitz RI. Influence of race, clinical, and other socio-demographic features on trial participation. J Clin Epidemiol. 2003; 56(4):304-309. [PubMed: 12767406]

13. Parikh NS, Parker RM, Nurss JR, Baker DW, Williams MV. Shame and health literacy: the unspoken connection. Patient Educ Couns. 1996; 27(1):33-39. [PubMed: 8788747]

14. Davis TC, Holcombe RF, Berkel HJ, Pramanik S, Divers SG. Informed consent for clinical trials: a comparative study of standard versus simplified forms. J Natl Cancer Inst. 1998; 90(9):668-674. [PubMed: 9586663]

15. Rossi M, McClellan R, Chou L, Davis K. Informed consent for ankle fracture surgery: patient comprehension of verbal and videotaped information. Foot Ankle Int. 2004; 25(10):756-762. [PubMed: 15566709]

16. Flory J, Emanuel E. Interventions to improve research participants' understanding in informed consent for research: a systematic review. JAMA. 2004; 292(13):1593-1601. [PubMed: 15467062]

17. Davis TC, Long SW, Jackson RH, et al. Rapid estimate of adult literacy in medicine: a shortened screening instrument. Fam Med. 1993; 25(6):391-395. [PubMed: 8349060]

18. Doak, C.; Doak, L.; Root, J. Teaching Patients With Low Literacy Skills. 2nd ed.. Philadelphia, PA: JB Lippincott; 1996.

19. Murthy VH, Krumholz HM, Gross CP. Participation in cancer clinical trials: race-, sex-, and agebased disparities. JAMA. 2004; 291(22):2720-2726. [PubMed: 15187053]

20. Naarden AL, Cissik J. Informed consent. Am J Med. 2006; 119(3):194-197. [PubMed: 16490461] 